Article

\title{
Impact of Emotional Perceived Value on the Uncertain Evolution of the Housing Bubble
}

\author{
Yang Tang ${ }^{1, *} \mathbb{( D )}$, Kairong Hong ${ }^{1, *}$, Yucheng Zou ${ }^{1, *}$ and Yanwei Zhang ${ }^{2, *}$ \\ 1 School of Business, Central South University, Changsha 410083, China \\ 2 College of Public Administration, Huazhong University of Science and Technology, Wuhan 430074, China \\ * Correspondence: 171601034@csu.edu.cn (Y.T.); hongkair@csu.edu.cn (K.H.); 191611002@csu.edu.cn (Y.Z.); \\ bsonyan@hust.edu.cn (Y.Z.); Tel.: +86-135-4855-5668 (Y.T.)
}

Citation: Tang, Y.; Hong, K.; Zou, Y.; Zhang, Y. Impact of Emotional Perceived Value on the Uncertain Evolution of the Housing Bubble. Mathematics 2021, 9, 1543. https:// doi.org/10.3390/math9131543

Academic Editors: Aleksandra Gawel, Miloš S. Krstić, Katarzyna

Mroczek-Dąbrowska and David Barilla

Received: 24 May 2021

Accepted: 27 June 2021

Published: 1 July 2021

Publisher's Note: MDPI stays neutral with regard to jurisdictional claims in published maps and institutional affiliations.

Copyright: (c) 2021 by the authors. Licensee MDPI, Basel, Switzerland. This article is an open access article distributed under the terms and conditions of the Creative Commons Attribution (CC BY) license (https:// creativecommons.org/licenses/by/ $4.0 /)$.

\begin{abstract}
In China, the housing bubble is not only an economic issue but also an important social and political issue. According to game theory, the housing bubble is an equilibrium result of the interaction between policy environment and participants' behavior. In this process, due to the interaction between speculation, regulation, and emotions, the development and evolution of the housing bubble are faced with uncertainty. Different from traditional econometric analysis, this article adopts the evolutionary game analysis method in order to establish a multi-stage evolutionary game analysis framework for the housing bubble. Firstly, by analyzing the emotional perceived value of related subjects under optimism, pessimism, and uncertainty, this article explores the mechanism of emotional perceived value on the housing bubble under the condition of inconsistent policy objectives. Secondly, it introduces emotional perceived value into the evolutionary game analysis framework of housing bubbles and analyzes the strategic combination and game equilibrium between investors and local governments under different emotions. Finally, taking Hainan province as an example, it conducts a MATLAB numerical simulation on the uncertain evolution of the housing bubble and proposes a staged strategy combination to deal with the housing bubble. The results show that: (1) emotional perceived value is affected by policy environment; (2) changes in the strength of policy effects make emotional perceived value change, which has different incentive effects on investors' speculation and local governments' regulation; (3) there are differences in emotional perceived value in different stages, which improves the uncertainty of the game equilibrium result between investors and local governments; and (4) considering the evolutionary characteristics of the housing bubble in different stages, its countermeasures should not only prevent insufficient regulation but also avoid excessive regulation. The above conclusions can provide theoretical and practical references for predicting the behavior of real estate investors, identifying the evolution mechanisms and rules of real estate bubbles and formulating relevant regulatory policies.
\end{abstract}

Keywords: housing bubbles; emotional perceived value; uncertain evolutionary game; MATLAB numerical simulation

\section{Introduction}

Real estate is the general term for house and land. Nowadays, the traditional attributes of real estate have gradually changed from durable consumer goods and production factors to attributes that are both investment tools [1]. Compared with housing demand, speculative demand is more likely to promote an unreasonable rise in housing prices, accelerate the formation of bubbles, and worsen housing affordability, which have a profound impact on regional economies [2]. In recent years, with the rapid rise of housing prices in China's large and medium-sized cities, the housing bubble has gradually become a hot topic and an important object of national economic policy research. It is generally believed that the essence of housing bubbles is a price movement phenomenon, which is caused by the continuous rise of housing prices due to housing speculation [3]. In this process, investors 
often have psychological expectations for a systematic rise in housing prices in the future, which further encourages them to adopt group speculation [4]. However, the housing bubble is unstable. When it expands to a certain extent it may burst, which would have a serious impact on the national economy. For example, in the 1990s, with the bursting of Japan's bubble economy, Japan's domestic economy suffered heavy losses and plunged into a long-term recession. In 2008, the emergence of the US subprime mortgage crisis triggered global financial turmoil. In China, the huge contribution of real estate to the national economy and the imperfect housing system make development positioning of real estate relatively vague, which is manifested in the interweaving and multi-management of the political, economic, social, investment, consumption, and other functions of real estate. It also causes a rapid rise in housing prices, excessively high housing prices, huge housing bubbles, and the "real estateization" of the economy [5]. According to the "Questionnaire Report on Urban Depositors in the Fourth Quarter of 2016" issued by the People's Bank of China, $52.7 \%$ of urban residents find current housing prices unacceptable. At the press conference of China's NPC and CPPCC in 2021, Guo Shuqing, Party Secretary of the People's Bank of China and Chairman of the China Banking and Insurance Regulatory Commission, pointed out that the core problem of real estate is that the bubble is relatively large and represents "the biggest gray rhino" that threatens financial security. He believed that many people buy houses not for living, but for investment or speculation. Therefore, in China and many other countries, the housing bubble is not only an economic issue but also an important social and political issue [6]. This requires further analysis of the causes of the housing bubble and exploration of the evolution process of the housing bubble, so as to provide a basis for the government to formulate regulatory policies and a reference for the decisions of homebuyers.

In recent years, China's housing market has shown unprecedented prosperity. According to the statistics of the " 2015 China Statistical Yearbook", since 2011 the sales area of commercial housing in China has been maintained at more than 1 billion square meters every year and the total sales amount has exceeded 5 trillion CNY every year, showing an increasing trend year by year. Especially in some popular areas, the rise in housing prices in some cities is crazy. For example, Hainan Province, which is one of the regions with a relatively large housing bubble, is also the only province in China that has experienced a housing crash. According to the GDP ranking of 31 provinces in the first half of 2018 released by the China Bureau of statistics, the GDP of Hainan Province is 243.488 billion CNY, ranking fourth from the bottom in China. In June of the same year, among the 70 large and medium-sized cities in the country, Haikou ranked first in the country for the sales price of newly built commercial housing (with a month-on-month increase of 3.9\%), followed by Sanya. Different from other provinces in China, the rise of house prices in Hainan province is less affected by its economic development than by market speculation caused by favorable policies. Since the establishment of Hainan province, its housing market has experienced three main rises. In 1988, Hainan province was officially established and became the largest special economic zone in China, making it a holy land for "gold diggers" all over the country. According to the statistics of China's housing market yearbook (1996), the average price of commercial housing in Hainan Province was $1400 \mathrm{CNY} / \mathrm{m}^{2}$ in 1991 , rose sharply to $5000 \mathrm{CNY} / \mathrm{m}^{2}$ in 1992 , and reached a peak of $7500 \mathrm{CNY} / \mathrm{m}^{2}$ in 1993 . With the release of the State Council's "Opinions on Current Economic Conditions and Strengthening Macroeconomic Control" in 1993, which covered 16 powerful control measures, the housing bubble in Hainan Province burst immediately. In 2010, the State Council issued the "Opinions on Promoting the Construction and Development of Hainan's International Tourism Island", proposing a national strategy of positioning Hainan province as an international tourism island, which ushered in a second wave of the skyrocketing housing market in Hainan province. In 2018, on the 30th anniversary of the founding of Hainan province, the state once again proposed the establishment of a Free Trade Pilot Zone and a free trade port with Chinese characteristics in Hainan province, which ushered in the third round of a surge in the Hainan housing market. Internationally, the "price-to-income 
ratio" is generally used to measure the difficulty of buying a house in a city, and its normal range is generally between three and six times. According to the ranking of the housing price-to-income ratio of major cities in China in 2019, the housing price-to-income ratio of Sanya is 29.62 and that of Haikou is 15.61, both far exceeding the international normal level. Rising housing prices not only make it more difficult for rigid demanders to buy houses, but also further widens the gap between the rich and the poor, which has a serious impact on social stability. Faced with abnormal fluctuations in housing prices, many scholars have used China's real estate data to calculate the basic value, speculative bubble, and bubble degree of real estate, concluding that a real estate bubble in China has already occurred and is relatively serious [3,7-9].

To squeeze out the housing bubble and promote the sustainable development of the housing market, China's regulatory efforts are constantly increasing. In 2016, the Central Economic Work Conference clearly stated that houses are for the living, not for speculation, and established a housing management system and a long-term mechanism in line with China's national conditions and market rules. In 2017, the 15th meeting of the Central Finance and Economics Leading Group further reiterated the above principles. Since then, most cities have successively introduced more stringent housing regulation policies, including increasing housing supply, curbing housing demand, and cracking down on housing speculation, and have been committed to returning housing to its original residential function. However, considering the serious dependence of GDP on housing, the government's work report in 2017 proposed that it is necessary to squeeze out the housing bubble in hot cities while avoiding large ups and downs in the housing market. Moreover, the inconsistency of policy objectives has caused the effects of implementing many policies to not always be significant, and housing prices in many cities are still high and difficult to shake. Furthermore, in some popular cities the more the local government regulates, the more the local housing prices rise, which has aroused widespread societal concerns.

Actually, real estate has characteristics such as fixed locations, asymmetric market information, and imperfect competition, which means that the housing market is not an effective market in the economic sense. In addition to the impact of market fundamentals such as disposable income, housing supply, population size, and GDP, housing prices may also be affected by favorable event expectations, policy expectations and other factors [10]. However, behavioral economics believes that investment behavior includes the three processes of market cognition, sentiments, and will, and that sentiments play an important role in determining that the subjects of real estate market have limited rational investment behavior. De Long et al. think that market sentiment represents an investors' optimistic or pessimistic view on the market [11]. In the housing market, market sentiment reflects market participants' perceptions, expectations, and evaluations of the housing markets current status and prospects, and it has an impact on market supply, demand, prices, transaction volume, and investment. Moreover, market speculation is also the embodiment of market participants' emotions, which will have a stronger catalytic effect on the housing market and lead to the emergence of a housing bubble [12]. Therefore, the utility value of housing to investors includes not only the use-value of the housing itself but also the option value of the housing [13]. This article believes that market speculation and government regulation are mutually beneficial competition games. In this process, the inconsistency of policy objectives triggers fluctuations in market sentiment, which makes the development and evolution of a housing bubble face uncertainty. At present, there are relatively more studies on the influence of market sentiment on securities and financial markets at home and abroad, while there are relatively few studies on the housing field. Therefore, based on behavioral economics and game theory, this article explores the influence mechanism of market sentiment on the housing bubble under the condition of inconsistent policy objectives, clarifies the evolution of the housing bubble under different market sentiments, and provides new ideas for the prevention and control of the housing bubble, which has important practical value. The rest of this paper is organized as follows: the second section is a literature review, summarizing the research on the impact of speculation, regulation, 
market sentiment and policy environment on the housing bubble, as well as the related research on the evolution and game of the housing bubble; the third section is the model construction; the fourth section is numerical simulation analysis; and the fifth section puts forward the conclusions and policy recommendations.

\section{Literature Review}

\subsection{Research on the Impact of Speculation on the Housing Bubble}

For a long time, research on the relationship between asset speculation and bubbles has attracted the attention of economists. Hirshleifer and Feiger believe that investors' subjective belief differences induce speculation, resulting in systematic deviation of asset prices and, eventually, the formation of asset bubbles [14,15]. Kindleberger believes that the essence of asset speculation is that inside speculators raise asset prices and sell them to outside speculators at peak times [16]. As a result, outside speculators will buy at high prices and sell at low prices. At the same time, investment income and investment risk are two important indicators that determine whether investors choose to speculate. Among them, investment income mainly evaluates future changes in asset prices, while investment risk mainly evaluates various uncertainties that affect investment income. The greater the uncertainty, the greater the investment risk [1].

In terms of research on housing speculation, there are currently two main ways to buy a house, namely through self-occupied house purchase and speculative house purchase. Self-occupied house purchases are mainly based on rigid demand, which has relatively limited driving effect on housing prices. Speculative house purchases regard the house as an investment product, motivated by anticipation of rising housing prices to make profits, which is the main source of rising housing prices. $\mathrm{Xu}$ analyzed the difference between housing investment and housing speculation, and their common point is to buy at low prices and sell at high prices [17]. However, housing investment is based on real demand, and housing speculation is initiated by one or more large-scale "initiators" and maintained by the "herd effect" of many "followers", which ultimately leads to economic bubbles. In this process, the speculative demand of high-income groups will have a "crowding out effect" on the consumer demand of low and middle-income groups [18], and may cause a chain reaction of house price increases in different areas of the city (that is, the transmission and diffusion from urban areas to the periphery of the city) [19]. Furthermore, Pawson and Martin also believed that owner occupiers and investors have different investment motivations, and that investors are more likely lead to a formulation of housing price bubble [20]. Long further divided housing speculation into developer speculation and housing speculation groups. After the developers purchase the land, they use the bank leverage to develop the housing market. When the land price or house price goes up, it gains profits by hoarding land or housing. The housing speculation group bought houses in batches from developers, and sold them by hoarding houses and raising housing prices [21].

In the research on the impact of speculation on housing bubbles, the current housing bubbles mainly include rational bubbles and irrational bubbles. Under the premise that the market is effective, a rational bubble means that under people's rational behavior and rational expectations, there is a rational bubble component in the price of assets in addition to reflecting the basic value, which is not the result of mispricing but reflects the future value deviation [22]. In addition, economic growth expectations, urbanization expectations, favorable event expectations, policy expectations and other factors are also important reasons for the housing bubble [23]. Kuang found that the higher the rational expectation of housing prices, the greater the market speculation and the greater the fluctuation of housing prices. When consumer demand dominates, the higher the house price and the smaller the fluctuation. When the speculative demand dominates, the higher the house price and the greater the fluctuation [24]. Market coordination failure, information asymmetry, or certain market imperfections often lead to the failure of market efficiency, resulting in the emergence of irrational bubbles [25]. Excessive speculation is the driving 
force for the formation of the housing bubble, and the violent fluctuation of housing prices is its inevitable consequence [12,26]. It is generally believed that there are rational traders and noise traders in the housing market [27]. Rational traders make decisions based on market fundamentals, while noise traders "chase the rise and kill the fall" based on past price movements. Case and Shiller conducted a questionnaire survey on American home buyers and found that after a period of steady rise in housing prices, home buyers will have adaptive expectations that housing prices will rise further. To avoid the situation of "don't buy now, you will not be able to afford it in the future", panic purchases broke out [28]. Zhou and Cao found that the positive feedback effect of demand expectation and price expectation led to an increase in housing demand with the increase of expected price [29]. In summary, speculation can promote a housing bubble. The market foundation can only partially determine the direction of housing prices, and market expectations, speculation and irrational behaviors can all have an impact on housing price fluctuations.

\subsection{Research on the Impact of Regulation Policies on the Housing Bubble}

The housing regulation policies in China, especially land regulation policies, have caused a lack of stable correspondence between housing prices and economic fundamentals [30]. Housing regulation policies have the dual goals of promoting the stable development of the housing market and maintaining macroeconomic stability, including demand regulation policies and supply regulation policies. Demand regulation policies mainly use administrative tools (such as purchase restriction and sales restriction), credit tools (such as the proportion of down payment for house purchase, preferential interest rate for housing loans), taxes (such as property tax), and other policy tools. Supply regulation policies mainly use policy tools such as land supply, social housing development, and housing enterprise regulation [31].

In terms of research on the impact of demand regulation policies, the purchase restriction policy will help reduce housing prices and housing transaction volume in the short term [32]. However, if the policy implementation period is short, housing prices may face a "retaliatory rebound." If the implementation period is too long, the housing market may be imbalanced for a long time. Han et al. and Li et al. found that the implementation effect of the purchase restriction policy varies significantly in different cities, and the decline in housing prices in small and medium-sized cities is greater than that in large cities. In cities where the demand for speculative housing is higher, the effect of the purchase restriction policy is more pronounced [33,34]. However, the demand regulation policy also has its own limitations. Chen and Gao found that the regulation policies can only be effective in the short term, but cannot suppress the accumulated expectations of house price rise [35]. Moreover, the increase of house price caused by the decrease of supply may offset the decrease of house price caused by the decrease of demand, thus weakening the influence of regulation policies on house prices [36]. In addition, different regulation policies have different applicable conditions. Research has found that the effect of money supply regulation is stronger when housing prices fluctuate sharply than that when housing prices are flat, and the effect of interest rate regulation is stronger when housing prices are flat than that when housing prices fluctuate significantly [37].

In terms of research on the impact of supply regulation policies, An and Wang believe that while land policies and affordable housing policies have a long-term significant impact on housing prices, there is also a significant time lag [38]. In terms of actual performance, the effect of housing demand suppression policies on the housing market is shown as a "fall in both volume and price", while the impact of land supply regulation policies on the housing market is shown as a "decline in price and increase in volume" [39]. In addition, land regulation policies have a significant threshold effect on housing price fluctuations [40]. Within a relatively small increase in housing prices, land policy regulation is relatively effective. However, within a relatively large increase in housing prices, the monetary regulation policy has a greater effect on housing prices. Sheng and Long believe that the phenomenon of "the more regulated and higher housing prices" is due to the functional 
imbalance between demand regulation policies and supply regulation policies [41]. The key to solving the problem lies in focusing on the effective combination of demand regulation and supply regulation, and taking into account the comprehensive application of shortterm regulation and long-term regulation. In summary, market regulation has a restraining effect on the housing bubble, but the effects of housing regulation policies are different under different conditions.

\subsection{Research on the Impact of Market Sentiment on the Housing Bubble}

The impact of market sentiment on the housing bubble mainly includes the impact on investor behavior and the impact on housing prices. Psychological research shows that sentiments can affect investors' behavioral decisions [42,43]. Market sentiment is somewhere between optimism and pessimism. The mutual fluctuations of optimism and pessimism have caused dynamic changes in the housing market [44,45]. Hu et al. found that when there is insufficient "noise" in the market, speculators will actively create "noise" to induce irrational investors [46]. Its induced behavior leads to excessive volatility of asset prices. In most cases, market sentiment is affected by environmental uncertainty [47]. Shiller found that sentiment will further encourage more investors to invest and improve their psychological expectations of the rising house prices, but that this feedback effect is not permanent [48]. Moreover, fluctuations in investors' heterogeneous sentiment may trigger asset price bubbles [49]. Lee and reed analyzed the pattern of basic housing price changes through the determinants of permanent and temporary components [50]. Environmental uncertainty will not only inhibit the overinvestment caused by the high investor sentiment, but also exacerbate the underinvestment caused by the sluggish investor sentiment. In addition, market sentiment will also affect investors' tolerance of risk [51]. Studies have found that there is a positive correlation between optimism and price bubbles, and pessimism will increase the degree of investor loss aversion, reduce investors' expectations of future returns, and make investors tend to take less risks [52].

The information asymmetry of market participants, the dispersion of information sources, and the increasing speculation in the market have made market sentiment an important factor affecting housing prices [53]. Many studies have shown that market sentiment has a positive impact on housing prices [54-56]. When market sentiment rises, the mentality of "buying late is not as good as buying early" makes housing prices rise. When market sentiment fell, this wait-and-see psychology reduces the scale of market demand, resulting in a fall in housing prices [57]. At the same time, pessimism has a more obvious impact on housing prices than optimism [58]. Investors' optimism about future fundamentals will increase the negative asymmetry of market volatility, while speculative sentiment will increase the positive asymmetry of market volatility [59]. To a certain extent, investor sentiment may weaken the regulatory effect of monetary policy on market volatility, which may cause the actual response of the market to monetary policy to deviate from the regulatory objectives [60]. Yin and Lu analyzed the formation process of investor expectations under the changing market sentiment, and concluded that market uncertainty will increase the probability of speculative bubbles [61]. Eddie et al. believe that market sentiment can reflect investors' optimistic (or pessimistic) expectations of future housing returns, resulting in temporary irrational prosperity in the housing market. However, over time the market price will eventually return to its intrinsic value [62]. In summary, market sentiment is affected by market expectations, uncertainty, and investment risks, and has a moderating effect on the expansion and contraction of the housing bubble.

\subsection{Research on the Impact of Policy Environment on Housing Bubble}

Uncertainty concerning economic policies and general macroeconomic behavior has an impact on house price fluctuations [63]. The fluctuation of housing market is closely related to monetary policy, globalization, and financial integration [64,65]. It is found that the increase of policy uncertainty has a greater impact on the decision-making of home purchases than the decrease of uncertainty [66]. Baker et al. extended the concept 
of uncertainty to economic policy uncertainty (EPU), and constructed the EPU index [67]. Hardouvelis et al. further constructed the Greek EPU index to test how economic policy uncertainty affects investment decisions and economic activities [68]. Posedel and Vizek compared the differences in the impact of macroeconomic policies on house prices between developed countries and transition countries, and found that the impact is asymmetric [69]. Meanwhile, there are path differences in the impact of policy uncertainty on housing prices. At the demand level, households can reduce their purchases of durable consumer goods such as houses [70]. Policy uncertainty may also increase stock premiums and increase borrowing costs, thereby reducing real estate-related investments [63]. In summary, the uncertainty of policy environment has an impact on investors' behavioral decisions.

\subsection{Research on the Evolution and Game of the Housing Bubble}

The housing speculation process involves beliefs, feedback effects, and other related factors, and it is the interaction between these different factors that promotes the rapid expansion and bursting of the housing bubble [71]. In the multi-dimensional interest game in the housing market, multiple interest groups such as housing consumer groups, housing speculators, developers, commercial banks, local governments, and the central government are involved. Ou divides different stakeholders into three different types of "market power". "Major raising force" promotes the rise of housing prices, "major dropping force" promotes the decline of housing prices, and "balance force" maintains the balance of the market [72]. Bao and Hommes studied the influence mechanism of market fundamentals and speculation on the formation of bubbles and collapses [73]. The nature of the boom and bust of the housing market is a conversion phenomenon between different market forces $[74,75]$. However, the stability of the housing market depends on the authenticity of the market and market behavior. When investors rely too much on the expected rules, the housing market will experience significant volatility [76].

The evolution process of the housing bubble is generally divided into four stages: bubble germination period, bubble formation period, bubble expansion period, and bubble burst period [77]. In different stages of evolution, investors' behavior is often affected by multiple behavior preferences such as reference dependence, loss aversion, and herding effect. The housing bubble originated from the overheated investment of developers and the speculative expectations of home buyers, which artificially created speculative demand in the housing market [78]. However, factors such as overconfidence, inflexible assets, and excess liquidity have promoted the rapid expansion of irrational bubbles [79]. When the housing bubble develops to a certain extent, due to the huge economic inertia, even if the government adopts strong market regulation measures, it is difficult to achieve a "soft landing" for the economy [3]. Therefore, it is precisely because of the particularity of the housing market in China that the local government cannot completely transfer the housing to the market for regulation. Instead, it should adopt the corresponding regulation policies to intervene in the housing market externally, according to the development and evolution of the housing bubble [80]. In summary, the evolution of the housing bubble is the equilibrium result of the mutual game of different stakeholders, and it shows phase characteristics according to the dynamic changes of speculative behavior and policy regulation.

Based on the above research, this article believes that the housing bubble is the result of the interaction between policy environment and participant behavior. Among them, the speculative behavior of investors is the driving force behind the formation of the housing bubble, and factors such as investment income, investment risks, and market expectations have an important impact on speculative behavior. The housing regulation has a restraining effect on the housing bubble, but its relatively strict applicable conditions make it difficult to maximize its policy effects. Market sentiment is affected by the policy environment and regulates the expansion and contraction of the housing bubble by influencing investor behavior and housing prices. Most of the existing studies are based on a single perspective, and the research methods are based on empirical analysis, ignoring the interaction between 
different influencing factors and their impact on the housing bubble. However, it is precisely due to the interaction between the three elements of speculation, regulation, and market sentiment that the development and evolution of the housing bubble are facing greater uncertainty. Different from the above method, this article draws on the evolutionary game analysis method of Friedman [81], puts the speculative behavior of investors and the regulatory behavior of local governments under different market sentiments, and constructs the uncertainty evolutionary game analysis framework of the housing bubble under the multidimensional market sentiment, aiming to show the dynamic evolution process of the housing bubble. Furthermore, taking Hainan province as an example, this article conducts a numerical simulation analysis on the uncertain evolution of the housing bubble and proposes prevention and regulation strategies for different stags of the housing bubble.

\section{Model Construction}

\subsection{The Perceived Value under the Multidimensional Market Sentiment}

The development and evolution of the housing bubble faces greater uncertainty due to the multidimensional market sentiment triggered by favorable regional policies and regulation policies in the housing market. On the one hand, favorable regional policies will stimulate investors' optimism and enhance their psychological expectations for the future rise of housing prices, which will produce positive incentives for housing speculation. On the other hand, the regulation policies in the housing market will lead to investors' pessimism and enhance their psychological expectations for the future decline of housing prices, which will produce negative incentives for housing speculation. Taking the housing market in Hainan province as an example, this article first discusses the perceived value of housing investors under optimism, pessimism, and uncertainty.

\subsubsection{The Perceived Value under Optimism}

As an international tourist island, a special economic zone, and a pilot free trade zone, Hainan province enjoys many national policy dividends. Through the media and housing developers' publicity and speculation, investors' optimism is soaring, which has become an important reason for the increase in housing prices. Since the construction of an international tourist island in Hainan province in 2010, the housing market Hainan province has rapidly heated up. Within five days after project approval, the sales of commercial housing in Hainan province exceeded the total sales of commercial housing in 2008, reaching 17.1 billion CNY. According to data released by the Hainan Provincial Bureau of Statistics, from 2014 to 2017, the transaction volume of commercial housing in Hainan province soared from 93.5 billion CNY to 271.3 billion CNY. As of 2017, the proportion of investors outside Hainan province has reached $88 \%$. Affected by market optimism, investors often have higher psychological expectations for house price increases, resulting in the actual transaction volume of the housing market in Hainan province being much higher than the normal demand. Taking the investors' actual house purchase expenditure as a reference point, when the investors' perceived value of the housing is higher than the actual house purchase expenditure, the investors' psychological utility is the gain. Based on this, the utility function of investors under optimism is:

$$
V_{H}=\left(P_{H}-P_{0}\right)^{\alpha}
$$

In Equation (1), $V_{H}$ is the investor's perceived value of the housing under optimism, $\alpha$ is the investor's optimism coefficient, which indicates the degree of investor's optimism about the housing market. When the investor is more optimistic about the housing market, the value of $\alpha$ will be larger, and $0<\alpha<1$. $P_{0}$ is the current price of the housing, $P_{H}$ is the expected price of the housing under optimism, $P_{H}>P_{0}$. 


\subsubsection{The Perceived Value under Pessimism}

In the face of the rapid rise of housing prices in Hainan province, the local government has issued a series of housing market regulation policies to curb speculation in the housing market. With the continuous increase in regulation, investors' pessimism has gradually increased, which has significantly reduced their housing speculation. For example, in April 2018, the People's Government of Hainan Province issued the "Notice on Further Stabilizing the Housing Market" and began to implement global purchase restriction policies based on the original regulation policies, which strictly restricted the purchase conditions, including adjusting the down payoff ratio of commercial loans to $70 \%$, restricting transactions within five years after purchase, and requiring buyers to provide proof of paying personal tax or social security for more than 60 months in Hainan province, which is known as the "most stringent regulation policy" in Hainan province. After the implementation of the above policies, the sales area and sales of the housing in Hainan province in 2018 decreased by $37.5 \%$ and $23.2 \%$ year-on-year, respectively. Affected by market pessimism, investors' psychological expectations for the decline of housing prices are constantly strengthening. Taking the investor's actual house purchase expenditure as a reference point, when the investor's perceived value of the housing is lower than the actual house purchase expenditure, the investor's psychological utility is a loss. Based on this, the utility function of investors under pessimism is:

$$
V_{L}=-\lambda\left(P_{0}-P_{L}\right)^{\beta}
$$

In Equation (2), $V_{L}$ is the investor's perceived value of the housing under pessimism, and $\beta$ is the investor's pessimism coefficient, which indicates the degree of investor's pessimism about the housing market. When the investor is more pessimistic about the housing market, the value of $\beta$ will be larger, and $0<\beta<1$. $P_{L}$ is the expected price of the housing under pessimism, $P_{L}<P_{0} . \lambda$ is the speculative risk coefficient, which is used to measure the risk of investors in housing speculation. When the local government's policy intervention and regulation are stronger, the speculative risk faced by investors will be greater, and $\lambda>1$.

\subsubsection{The Perceived Value under Uncertainty}

When favorable regional policies and regulation policies in the housing market take effect simultaneously, investor sentiment is often uncertain and is affected by both optimism and pessimism. There are two ways to divide traditional sentiments: discrete and continuous. Among them, the discrete type uses 0 and 1 to represent pessimism and optimism, respectively. The continuous type uses variables between 0 and 1 to express pessimism, uncertainty, and optimism [82]. Based on the above utility functions of investors under optimism and pessimism, this article draws on the continuous sentiment classification division, and constructs the utility function of investors under uncertainty:

$$
V_{M}=\gamma V_{H}+(1-\gamma) V_{L}=\gamma\left(P_{H}-P_{0}\right)^{\alpha}-(1-\gamma) \lambda\left(P_{0}-P_{L}\right)^{\beta}
$$

In Equation (3), $V_{M}$ is the investor's perceived value of the housing under uncertainty, $\gamma$ is the proportion of investors' optimism, $1-\gamma$ is the proportion of investors' pessimism, and $0 \leq \gamma \leq 1$. When $\gamma=0$ and $\gamma=1$, investors are pessimistic and optimistic respectively. When $\gamma$ is closer to 1 , it means that investors are more optimistic and less pessimistic. When $\gamma$ is closer to 0 , it means that investors are more pessimistic and less optimistic.

\subsection{Game Hypothesis}

The evolution of the housing bubble is essentially a dynamic game between investor speculation and local government regulation. In this process, investors will decide whether to speculate or not based on their comprehensive judgment on favorable regional policies and housing regulation policies. The local government will decide whether to regulate or 
not according to the future trend of housing prices. Thus, this article puts forward the first hypothesis.

Hypothesis 1. In the evolutionary game, only two players, the local government and investors, are considered. Both parties will continuously adjust their strategic choices based on their cognitive judgments and strive to maximize their respective interests. The strategy set of the local government is (regulation, no regulation), and the strategy set of the investor is (speculation, no speculation).

The function of local government determines that it should consider not only economic interests but also social interests. If the local government chooses regulation, it needs to pay the regulation cost. Otherwise, there is no need to pay. With the increase of regulation, the regulation cost will increase accordingly. When the local government chooses "regulation" and investors choose "no speculation", the local government will be rewarded by the superior government for its effective regulation and obtain corresponding social benefits. When the local government chooses "regulation" and the investor chooses "speculation", the local government will be punished by the superior government for ineffective regulation and cause corresponding social losses. When the local government chooses "no regulation" and the investors choose "speculation", the local government will be punished by the superior government for its ination and will cause greater social losses. When the local government chooses "no regulation" and the investors choose "no speculation," the local government has no gains or losses. Thus, this article puts forward the second hypothesis.

Hypothesis 2. The revenue and expenditure of the local government in the regulation of the housing market include five components: the regulation cost, the reward from the superior government, the punishment from the superior government, the social loss, and the social benefit.

Investors' perceived value of the housing market includes three types: the perceived value under optimism, pessimism, and uncertainty. When investors choose not to speculate, they do not buy houses. Therefore, whether the local government chooses to regulate or not, investors' perceived value of the housing is 0 . When there are favorable regional policies, if the investors choose "speculation" and the local government chooses "no regulation", the investors' perceived value of the housing is only affected by optimism. Moreover, if the investors choose "speculation" and the local government chooses "regulation", the investors' perceived value of the housing is affected by optimism and pessimism. Thus, this article puts forward the third hypothesis.

Hypothesis 3. Investors' speculative behavior is affected by market sentiment. Optimism has a positive incentive to housing speculation, while pessimism has a negative incentive to housing speculation.

There are speculative risks in housing speculation. When the investors choose "no speculation", there is no speculation risk. When the investors choose "speculation" and the local government chooses "no regulation ", the investors' speculative risk is not affected by the housing market regulation policy. When the investors choose "speculation" and the local government chooses "regulation", the investors' speculative risk is affected by the housing market regulation policies. As the local government increases their regulation, the lower the housing speculative gains will be and the greater the speculative losses will be. Thus, this article puts forward the fourth hypothesis.

Hypothesis 4. The level of speculation risk is related to the intensity of local government regulation. The stricter the local government's policy regulation is, the greater the investors' speculative risk will be.

Favorable regional policies and housing regulation policies have an uncertain impact on the value of the housing market. When investors choose not to speculate, they do not 
buy houses, so the housing value is not affected by favorable regional policies and housing regulation policies. When the investors choose "speculation" and the local government chooses "no regulation", the housing value is only affected by favorable regional policies, and the investors expect housing prices to rise. When the investors choose "speculation" and the local government chooses "regulation", the housing value is affected by both favorable regional policies and housing regulation policies. At this time, the investors' psychological expectations of housing prices are uncertain. Thus, this article puts forward the fifth hypothesis.

Hypothesis 5. The value of the housing market is uncertain. Favorable regional policies are expected to drive housing prices up, and the housing regulation policies are expected to drive housing prices down.

\subsection{Game Analysis}

Based on the above hypotheses, this article establishes the game payment matrix of the local government and the investors under the combination of four strategies, as shown in Table 1. The four strategies correspond to the four main stages of the development and evolution of the housing bubble, which are the bubble-free stage, the bubble germination and formation stage, the bubble expansion stage, and the bubble burst stage.

Table 1. The game payoff matrix of the local government and investors.

\begin{tabular}{ccc}
\hline \multirow{2}{*}{ Local Government } & \multicolumn{2}{c}{ Investors } \\
\cline { 2 - 3 } & Speculation $(\boldsymbol{\theta})$ & No Speculation $(1-\boldsymbol{\theta})$ \\
\hline \multirow{2}{*}{ Regulation $(\delta)$} & The third stage & The fourth stage \\
& $-C-F_{2}-W_{2}$ & $R-C+W_{3}$ \\
& $\gamma\left(P_{2}-P_{0}\right)^{\alpha_{2}}-$ & 0 \\
No regulation $(1-\delta)$ & $(1-\gamma) \lambda\left(P_{0}-P_{3}\right)^{\beta}$ & The first stage \\
& The second stage & 0 \\
& $-F_{1}-W_{1}$ & 0 \\
\hline
\end{tabular}

The first stage is the bubble-free stage. In this stage, the housing market is not affected by regional favorable policies and housing market regulation policies. The local government will choose "no regulation" and the investors will choose "no speculation". According to Hypothesis 2 and Hypothesis 3, the local government and the investors have no gains or losses (that is, the local government's payoff is 0 , and the investors' perceived value to the housing is 0 ).

The second stage is the bubble germination and formation stage. In this stage, the housing market is only affected by regional favorable policies. The local government will choose "no regulation" and the investors will choose "speculation". According to Hypothesis 2, for the local government, its inaction will be punished by the superior government and bear the corresponding social losses. Assuming that the superior government's penalty is $F_{1}$ and the social loss is $W_{1}$, the local government's payoff is $-F_{1}-W_{1}$. According to Hypothesis 3 and Hypothesis 5, investors' speculative behavior is only affected by market optimism, and the favorable regional policies make investors have psychological expectations of rising house prices. Assuming that the current price of the housing is $P_{0}$, the investors expected price of the housing is $P_{1}$, and $P_{1}>P_{0}$, and the investors optimism coefficient is $\alpha_{1}$, the investors perceived value to the housing is $\left(P_{1}-P_{0}\right)^{\alpha_{1}}$.

The third stage is the bubble expansion stage. In this stage, the housing market is affected by both regional favorable policies and housing market regulation policies, but the intensity of housing market regulation policies is relatively small. The local government will choose "regulation" and the investors will choose "speculation". According to Hypothesis 2, for the local government, its ineffective regulation will also be punished by the superior government and bear the corresponding social losses. Moreover, they will 
also need to pay regulation costs. Assuming that the regulation cost is $C$, the penalty from the superior government is $F_{2}\left(F_{2}<F_{1}\right)$, and the social loss is $W_{2}\left(W_{2}<W_{1}\right)$, then the local government's payoff is $-C-F_{2}-W_{2}$. According to Hypothesis 3, Hypothesis 4, and Hypothesis 5, investors' speculation is affected by both market optimism and market pessimism. The favorable regional policies make investors have psychological expectations for rising house prices, and the housing market regulation policies make investors face speculative risks, resulting in psychological expectations for falling house prices. Assuming that the investors' optimism ratio is $\gamma$, the pessimism ratio is $1-\gamma$, the investors' expected price of the housing under optimism is $P_{2}$, the investors' expected price of the housing under pessimism is $P_{3}$, the investors' optimism coefficient is $\alpha_{2}$, the pessimistic coefficient is $\beta$, the investment risk coefficient is $\lambda$, and the investors' perceived value of the housing is $\gamma\left(P_{2}-P_{0}\right)^{\alpha_{2}}-(1-\gamma) \lambda\left(P_{0}-P_{3}\right)^{\beta}$.

The fourth stage is the bubble burst stage. In this stage, the housing market is affected by both regional favorable policies and housing market regulation policies, but the intensity of housing market regulation policies is relatively large. The local government will choose "regulation" and the investors will choose "no speculation". According to Hypothesis 2, for the local government, its effective regulation will be rewarded by the superior government and obtain corresponding social benefits. Assuming that the regulation cost remains unchanged, the superior government's reward is $R$, and the social benefit is $W_{3}$, then the local government's payoff is $R-C+W_{3}$. According to Hypothesis 3 , affected by the local government's strict regulation policies, investors will not speculate in the housing. Therefore, investors are not affected by market sentiment and their perceived value of the housing is 0 .

\subsection{Evolution Analysis}

Assume that the probability of the local government choosing "regulation" is $\delta$, and the probability of choosing "non-regulation" is $1-\delta$. Assume also that the probability of the investors choosing "speculation" is $\theta$, and the probability of choosing "no speculation" is $1-\theta$. For the local government, the expected benefits when choosing "regulation" and "no regulation" are $E_{(\delta)}$ and $E_{(1-\delta)}$ respectively, and the average benefit is $E_{(G)}$, calculated as below:

$$
\begin{gathered}
E_{(\delta)}=\theta\left(-C-F_{2}-W_{2}\right)+(1-\theta)\left(R-C+W_{3}\right) \\
E_{(1-\delta)}=\theta\left(-F_{1}-W_{1}\right) \\
E_{(G)}=\delta E_{(\delta)}+(1-\delta) E_{(1-\delta)}
\end{gathered}
$$

When $E_{(\delta)}>E_{(G)}$, the expected benefits of the local government when choosing the "regulation" are greater than the average benefits. As time goes by, for the local government, the probability $\delta$ of choosing the "regulation" increases. When $E_{(1-\delta)}>E_{(G)}$, the expected benefits of the local government when choosing the "no regulation" strategy are greater than the average benefits, and the probability $\delta$ of choosing the "regulation" decreases over time. Therefore, the replication dynamics equation expressed as $F(\delta)$ for the local government to choose "regulation" can be achieved as follows:

$$
F(\delta)=\delta\left(E_{(\delta)}-E_{(G)}\right)=\delta(1-\delta)\left(E_{(\delta)}-E_{(1-\delta)}\right)=\delta(1-\delta)\left[\theta\left(-F_{2}-W_{2}+F_{1}+W_{1}-R-W_{3}\right)+\left(R-C+W_{3}\right)\right]
$$

Equation (7) shows that the change rate of probability $\delta$ of the local government's choice of "regulation" is proportional to the probability $\delta$ of local government's choice of "regulation" and the probability $1-\delta$ of "no regulation", and is also proportional to the payment difference $\theta\left(-F_{2}-W_{2}+F_{1}+W_{1}-R-W_{3}\right)+\left(R-C+W_{3}\right)$ between "regulation" and "no regulation". In addition, it is also related to the value of $\theta$, but not to the rate of change of $\theta$. 
For the investors, the expected benefits when choosing "speculation" and "no speculation" are $E_{(\theta)}$ and $E_{(1-\theta)}$, respectively, and the average benefit is $E_{(I)}$, calculated as below:

$$
\begin{gathered}
E_{(\theta)}=\delta\left[\gamma\left(P_{2}-P_{0}\right)^{\alpha_{2}}-(1-\gamma) \lambda\left(P_{0}-P_{3}\right)^{\beta}\right]+(1-\delta)\left(P_{1}-P_{0}\right)^{\alpha_{1}} \\
E_{(1-\theta)}=0 \\
E_{(I)}=\theta E_{(\theta)}+(1-\theta) E_{(1-\theta)}
\end{gathered}
$$

When $E_{(\theta)}>E_{(I)}$, the expected benefits of the investors when choosing the "speculation" are greater than the average benefits. As time goes by, the probability $\theta$ of choosing the "speculation" increases. When $E_{(1-\theta)}>E_{(I)}$, the expected benefits of the investors when choosing the "no speculation" strategy are greater than the average benefits, and the probability $\theta$ of choosing the "speculation" decreases over time. Therefore, the replication dynamics equation expressed as $F(\theta)$ for the investors to choose "speculation" can be achieved as follows:

$$
\begin{aligned}
F(\theta)= & \theta\left(E_{(\theta)}-E_{(I)}\right)=\theta(1-\theta)\left(E_{(\theta)}-E_{(1-\theta)}\right)=\theta(1-\theta) E_{(\theta)} \\
= & \theta(1-\theta)\left\{\delta \left[\begin{array}{l}
\left.\left.\gamma\left(P_{2}-P_{0}\right)^{\alpha_{2}}-(1-\gamma) \lambda\left(P_{0}-P_{3}\right)^{\beta}\right]+(1-\delta)\left(P_{1}-P_{0}\right)^{\alpha_{1}}\right\} \\
=\theta(1-\theta)\left\{\delta\left[\gamma\left(P_{2}-P_{0}\right)^{\alpha_{2}}-(1-\gamma) \lambda\left(P_{0}-P_{3}\right)^{\beta}-\left(P_{1}-P_{0}\right)^{\alpha_{1}}\right]+\left(P_{1}-P_{0}\right)^{\alpha_{1}}\right\}
\end{array}\right.\right.
\end{aligned}
$$

Equation (11) shows that the change rate of probability $\theta$ of the investors' choice of "speculation" is proportional to the probability $\theta$ of the investors' choice of "speculation" and the probability $1-\theta$ of "no speculation", and is also proportional to the payment difference $\delta\left[\gamma\left(P_{2}-P_{0}\right)^{\alpha_{2}}-(1-\gamma) \lambda\left(P_{0}-P_{3}\right)^{\beta}-\left(P_{1}-P_{0}\right)^{\alpha_{1}}\right]+\left(P_{1}-P_{0}\right)^{\alpha_{1}}$ between "speculation" and "no speculation". In addition, it is also related to the value of $\delta$, but not to the rate of change of $\delta$.

\subsection{Stability Analysis}

According to Friedman's method, this article first analyzes the stability of the local equilibrium point through the Jacobian matrix, and then analyzes the stability of the local equilibrium point of the dynamic replication system, to find the evolutionary stability strategy (ESS) of the local government and investors. The specific steps are as follows:

First of all, to obtain the above-mentioned equilibrium points, we first set equations $F(\delta)=F(\theta)=0$, the five possible local equilibrium points of the replication dynamic system can be obtained, which are $D_{1}(0,0), D_{2}(0,1), D_{3}(1,0), D_{4}(1,1)$, and $D_{5}\left(\delta^{*}, \theta^{*}\right)$. Among them, $\delta^{*}=\frac{-\left(P_{1}-P_{0}\right)^{\alpha_{1}}}{\gamma\left(P_{2}-P_{0}\right)^{\alpha_{2}}-(1-\gamma) \lambda\left(P_{0}-P_{3}\right)^{\beta}-\left(P_{1}-P_{0}\right)^{\alpha_{1}}}, \theta^{*}=\frac{-R+C-W_{3}}{-F_{2}-W_{2}+F_{1}+W_{1}-R-W_{3}}$.

Secondly, in order to obtain the Jacobian matrix of the dynamic replication system, we need to calculate the partial derivatives of $F(\delta)$ and $F(\theta)$ with respect to $\delta$ and $\theta$.

$$
\begin{gathered}
\frac{\partial F(\delta)}{\partial \delta}=(1-2 \delta)\left[\theta\left(-F_{2}-W_{2}+F_{1}+W_{1}-R-W_{3}\right)+\left(R-C+W_{3}\right)\right] \\
\frac{\partial F(\delta)}{\partial \theta}=\delta(1-\delta)\left(-F_{2}-W_{2}+F_{1}+W_{1}-R-W_{3}\right) \\
\frac{\partial F(\theta)}{\partial \delta}=\theta(1-\theta)\left[\gamma\left(P_{2}-P_{0}\right)^{\alpha_{2}}-(1-\gamma) \lambda\left(P_{0}-P_{3}\right)^{\beta}-\left(P_{1}-P_{0}\right)^{\alpha_{1}}\right] \\
\frac{\partial F(\theta)}{\partial \theta}=(1-2 \theta)\left\{\delta\left[\gamma\left(P_{2}-P_{0}\right)^{\alpha_{2}}-(1-\gamma) \lambda\left(P_{0}-P_{3}\right)^{\beta}-\left(P_{1}-P_{0}\right)^{\alpha_{1}}\right]+\left(P_{1}-P_{0}\right)^{\alpha_{1}}\right\}
\end{gathered}
$$
formula:

The Jacobian matrix $J$ and trace $\operatorname{Tr}(J)$ of the system are calculated from the following

$$
J=\left(\begin{array}{ll}
\frac{\partial F(\delta)}{\partial \delta} & \frac{\partial F(\delta)}{\partial \theta} \\
\frac{\partial F(\theta)}{\partial \delta} & \frac{\partial F(\theta)}{\partial \theta}
\end{array}\right)
$$




$$
\operatorname{Tr}(J)=\frac{\partial F(\delta)}{\partial \delta}+\frac{\partial F(\theta)}{\partial \theta}
$$

Finally, by substituting the above local equilibrium points into the partial derivatives of $F(\delta)$ and $F(\theta)$, and combining with the specific expression of Jacobian matrix, four Jacobian matrices can be obtained.

$$
\begin{gathered}
J(0,0)=\left(\begin{array}{cc}
R-C+W_{3} & 0 \\
0 & \left(P_{1}-P_{0}\right)^{\alpha_{1}}
\end{array}\right) \\
J(0,1)=\left(\begin{array}{cc}
-F_{2}-W_{2}+F_{1}+W_{1}-C & 0 \\
0 & -\left(P_{1}-P_{0}\right)^{\alpha_{1}}
\end{array}\right) \\
J(1,0)=\left(\begin{array}{cc}
-\left(R-C+W_{3}\right) & 0 \\
0 & \gamma\left(P_{2}-P_{0}\right)^{\alpha_{2}}-(1-\gamma) \lambda\left(P_{0}-P_{3}\right)^{\beta}
\end{array}\right) \\
J(1,1)=\left(\begin{array}{cc}
F_{2}+W_{2}-F_{1}-W_{1}+C & 0 \\
0 & -\gamma\left(P_{2}-P_{0}\right)^{\alpha_{2}}+(1-\gamma) \lambda\left(P_{0}-P_{3}\right)^{\beta}
\end{array}\right)
\end{gathered}
$$

The above-mentioned equilibrium points are the result of continuous adjustment and improvement after the random combination of the local government and the investors' strategy selection. If and only if $\operatorname{Det}(J)>0$ and $\operatorname{Tr}(J)<0$, then the equilibrium point is the evolutionary stable strategy (ESS). Thus, the determinants and traces of the above equilibrium points are obtained, as shown in Table 2.

Table 2. Determinants and traces of equilibrium points.

\begin{tabular}{lcc}
\hline $\begin{array}{l}\text { Equilibrium } \\
\text { Points }\end{array}$ & $\operatorname{Det}(J)$ and $\operatorname{Tr}(J)$ \\
\hline$D_{1}(0,0)$ & $\begin{array}{c}\operatorname{Det}(J) \\
\operatorname{Tr}(J)\end{array}$ & $\left(R-C+W_{3}\right)\left(P_{1}-P_{0}\right)^{\alpha_{1}}$ \\
\hline$D_{2}(0,1)$ & $\operatorname{Det}(J)$ & $\left(R-C+W_{3}\right)+\left(P_{1}-P_{0}\right)^{\alpha_{1}}$ \\
\hline$D_{3}(1,0)$ & $\operatorname{Tr}(J)$ & $\left(-F_{2}-W_{2}+F_{1}+W_{1}-C\right)-\left(P_{1}-P_{0}\right)^{\alpha_{1}}$ \\
& $\operatorname{Det}(J)$ & $-\left(R-C+W_{3}\right)\left[\gamma\left(P_{2}-P_{0}\right)^{\alpha_{2}}-(1-\gamma) \lambda\left(P_{0}-P_{3}\right)^{\beta}\right]$ \\
& $\operatorname{Tr}(J)$ & $-\left(R-C+W_{3}\right)+\left[\gamma\left(P_{2}-P_{0}\right)^{\alpha_{2}}-(1-\gamma) \lambda\left(P_{0}-P_{3}\right)^{\beta}\right]$ \\
\hline$D_{4}(1,1)$ & $\operatorname{Det}(J)$ & $\left(F_{2}+W_{2}-F_{1}-W_{1}+C\right)\left[-\gamma\left(P_{2}-P_{0}\right)^{\alpha_{2}}+(1-\gamma) \lambda\left(P_{0}-P_{3}\right)^{\beta}\right]$ \\
& $\operatorname{Tr}(J)$ & $\left(F_{2}+W_{2}-F_{1}-W_{1}+C\right)-\gamma\left(P_{2}-P_{0}\right)^{\alpha_{2}}+(1-\gamma) \lambda\left(P_{0}-P_{3}\right)^{\beta}$ \\
\hline$D_{5}\left(\delta^{*}, \theta^{*}\right)$ & $\operatorname{Det}(J)$ & 0 \\
& $\operatorname{Tr}(J)$ & 0 \\
\hline
\end{tabular}

According to Table 2, when $\left(-F_{2}-W_{2}+F_{1}+W_{1}-C\right)<0$ and $-\left(P_{1}-P_{0}\right)^{\alpha_{1}}<0$, the ESS of the system is $(0,1)$, in which the evolutionary stable equilibrium strategy of both parties in the game is (no regulation, speculation). When $-\left(R-C+W_{3}\right)<0$ and $\left[\gamma\left(P_{2}-P_{0}\right)^{\alpha_{2}}-(1-\gamma) \lambda\left(P_{0}-P_{3}\right)^{\beta}\right]<0$, the ESS of the system is $(1,0)$, in which the evolutionary stable equilibrium strategy of both parties in the game is (regulation, no speculation). When $\left(F_{2}+W_{2}-F_{1}-W_{1}+C\right)<0$ and $\left[-\gamma\left(P_{2}-P_{0}\right)^{\alpha_{2}}+(1-\gamma) \lambda\left(P_{0}-P_{3}\right)^{\beta}\right]<0$, the ESS of the system is $(1,1)$, in which the evolutionary stable equilibrium strategy of both parties in the game is (regulation, speculation). Because $\left(P_{1}-P_{0}\right)^{\alpha_{1}}>0$, when $\left(R-C+W_{3}\right)>0, \operatorname{Det}(J)>0$ and $\operatorname{Tr}(J)>0$. When $\left(R-C+W_{3}\right)<0, \operatorname{Det}(J)>0$ and $\operatorname{Tr}(J)$ is uncertain. Therefore, $(0,0)$ is not ESS. 


\section{MATLAB Numerical Simulation}

In order to visually reflect the long-term impact of policy changes on housing prices, based on the availability of data, we collatde housing price data from 2017 to 2019 in Sanya, the hottest real estate investment in Hainan, to illustrate this impact process. Before the introduction of major favorable policies in Hainan, the average housing price in Sanya in 2017 was $21,901 \mathrm{CNY} / \mathrm{m}^{2}$. In 2018, after the introduction of major favorable policies, housing prices in Sanya rose accordingly. The average housing price in Sanya was 30,959 CNY $/ \mathrm{m}^{2}$, an increase of $41.3 \%$ from 2017 , and the highest price exceeded $33,000 \mathrm{CNY} / \mathrm{m}^{2}$. Since then, with the release of the most stringent housing regulation policy in Hainan, the soaring trend of housing prices in Sanya had been curbed, and began to gradually fall. By the end of 2019, the real estate price in Sanya City had dropped to about $28,000 \mathrm{CNY} / \mathrm{m}^{2}$, which is $15 \%$ lower than the highest price in 2018 , and continues to decline. The trend of house prices is shown in Figure 1.

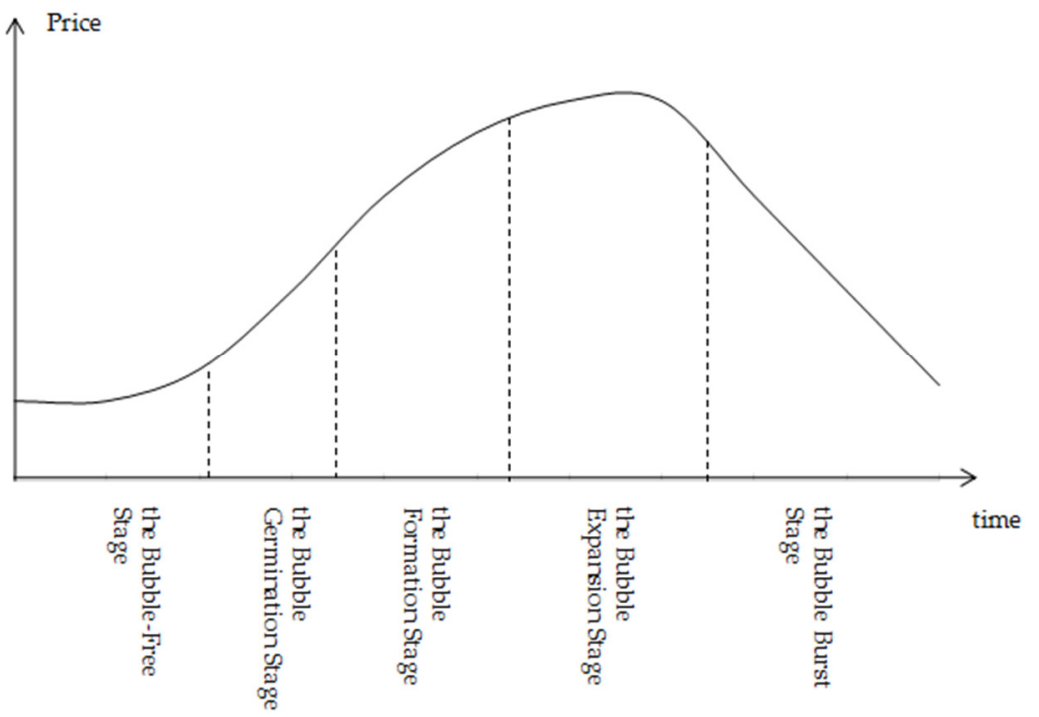

Figure 1. The evolution stage of housing bubbles.

On this basis, this article uses MATLAB software to simulate the uncertain evolution of the housing bubble under the multi-dimensional market sentiment based on the background that China announced the construction of the Free Trade Pilot Zone and the Free Trade Port in Hainan province with Chinese characteristics on 13 April 2018. Based on the time series of the housing bubble evolution, the development and evolution of the housing bubble in Hainan province are divided into five stages: the bubble-free stage (before 13 April), the bubble germination stage (13 April), the bubble formation stage (14 April-21 April), the bubble inflation stage (14 April-21 April), and the bubble burst stage (22 April). According to the evolution results of different stages, we put forward corresponding prevention and regulation strategies. The simulation results are shown in Figures 2-6, where the horizontal axis represents the evolution time, the simulation period is set as 10, and the vertical axis represents the probability of game players' strategy selection, which evolves in the range of 0 to 1 . The initial probability is assumed $\delta=\theta=0.5$, which means that the local government and investors both choose between different strategies with an initial probability of 0.5 , and the values of related parameters are strictly limited within the bounds. 


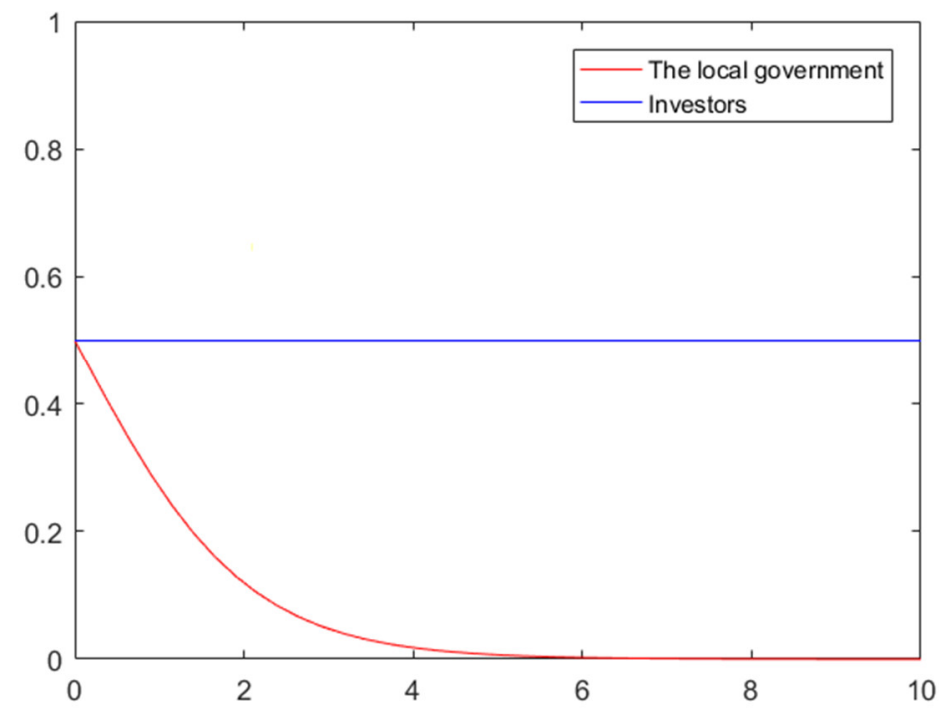

Figure 2. Simulation results in the bubble-free stage.

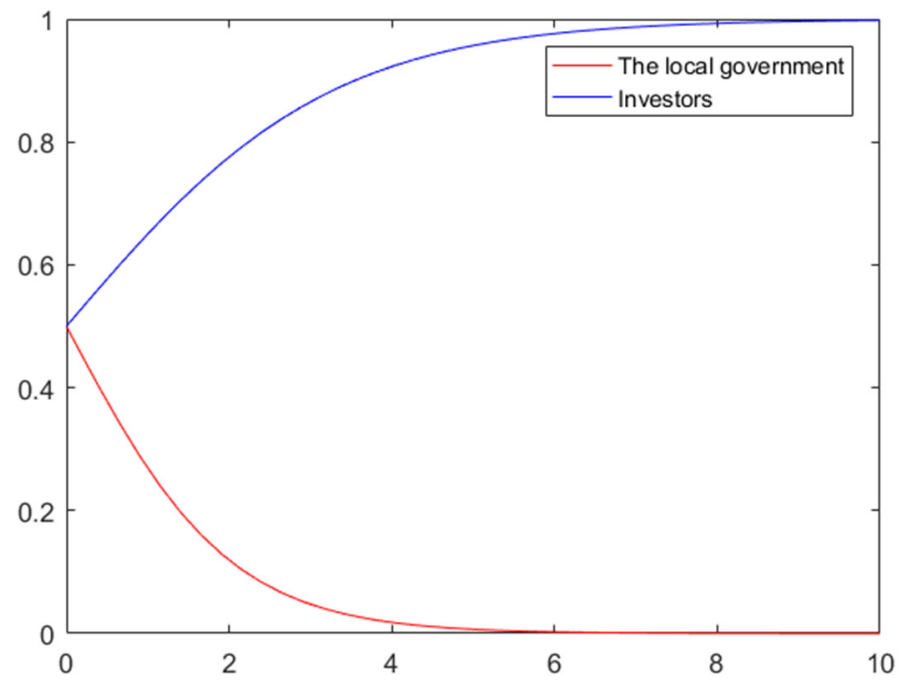

Figure 3. Simulation results in the bubble germination stage.

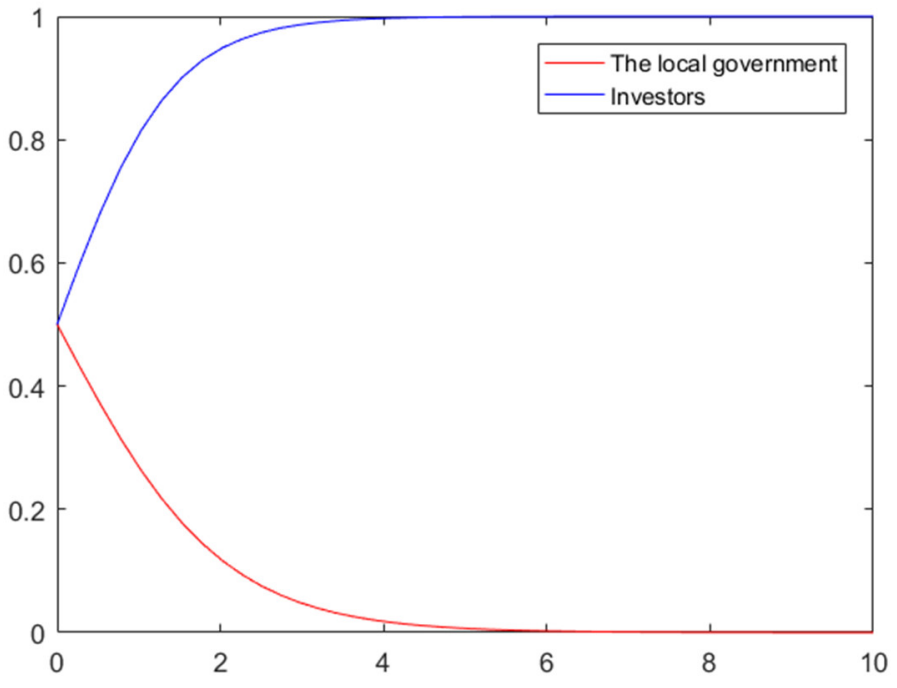

Figure 4. Simulation results in the bubble formation stage. 


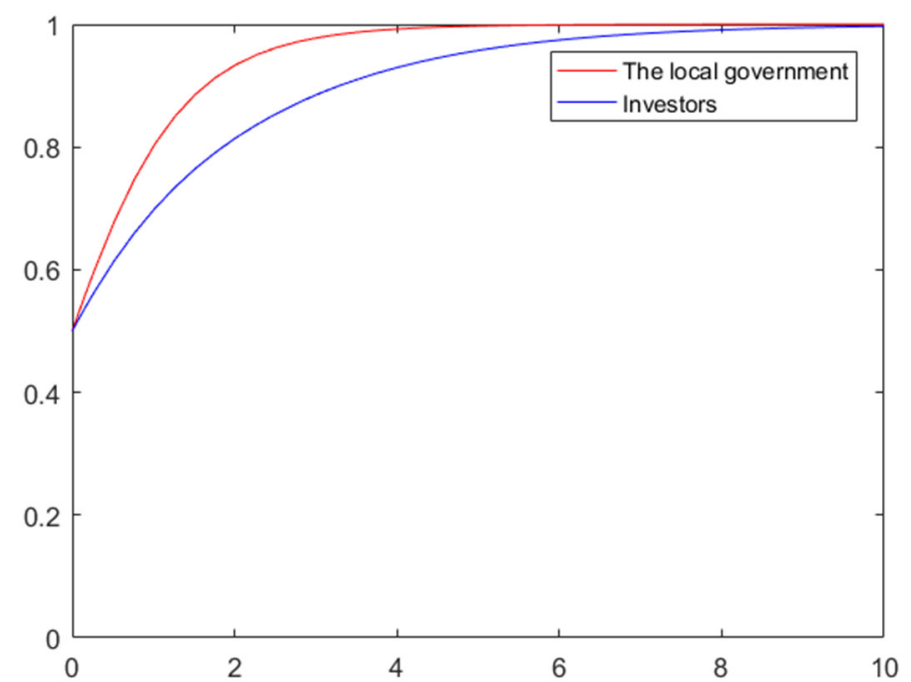

Figure 5. Simulation results in the bubble expansion stage.

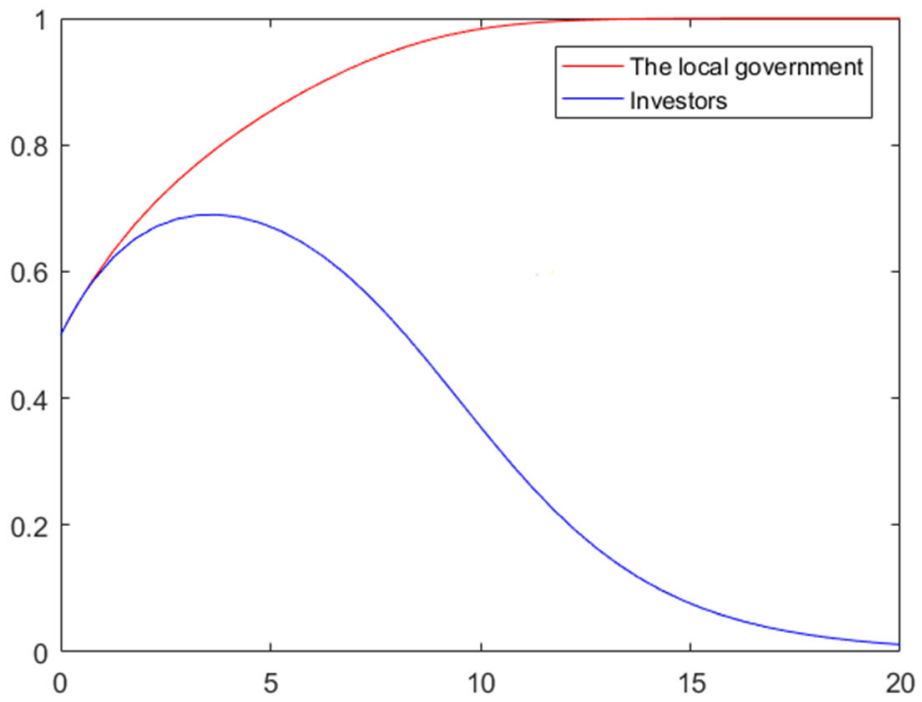

Figure 6. Simulation results in the bubble burst stage.

\subsection{Numerical Simulation Analysis in the Bubble-Free Stage}

Before 13 April 2018, the state had not yet announced a major development strategy for the construction of the Pilot Free Trade Zone and the Free Trade Port with Chinese characteristics in Hainan province. During this period, the housing prices in Hainan province can be regarded as the equilibrium price of supply and demand under normal market transactions. At this stage, the local government did not generate additional gains and losses, so its initial assumptions are set as: $F_{1}=F_{2}=0, W_{1}=W_{2}=W_{3}=0, R=0$, $C=1$. Meanwhile, the investors had no psychological expectations of housing prices rising or falling in the short term, and their market sentiment had no obvious fluctuations and were uncertain, so its initial assumptions are set as $P_{1}=P_{2}=P_{3}=P_{0}=1, \lambda=1.2$, $\gamma=0.5, \alpha_{1}=\alpha_{2}=\beta=0.5$. The simulation result is shown in Figure 2 .

It can be seen from Figure 2 that when $-C-F_{2}-W_{2}<-F_{1}-W_{1}$ and $R-C+W_{3}<0$, the local government tends to choose "no regulation". However, since $\gamma\left(P_{2}-P_{0}\right)^{\alpha_{2}}-$ $(1-\gamma) \lambda\left(P_{0}-P_{3}\right)^{\beta}=0$ and $\left(P_{1}-P_{0}\right)^{\alpha_{1}}=0$, the investor's strategic choice is uncertain. The above results show that the investors' behavior decisions are more affected by market factors, and show randomness and uncertainty in the housing transactions. On the other hand, since the local government has no extra revenue and needs to pay the extra regulation cost to choose "regulation", it has no regulation motivation and tends to choose "no regula- 
tion". Therefore, the game equilibrium result of this stage is (no regulation, speculation/no speculation). At this stage, the local government can strengthen the monitoring of house price fluctuations and market transaction volume before the release of favorable policies, so as to make adequate preparations for the possible housing speculation after the release of favorable policies.

\subsection{Numerical Simulation Analysis in the Bubble Germination Stage}

On 13 April 2018, at the 30th Anniversary Conference of Hainan Province and Hainan Special Economic Zone, President Xi Jinping announced that the state supports Hainan province to build a pilot free trade zone and a free trade port with Chinese characteristics, which immediately triggered a rise in housing prices. On the one hand, the favorable policy has enhanced the psychological expectation of investors for the future rise of housing prices. On the other hand, due to the lag of local government regulation, investors are only affected by market optimism at this stage. Accordingly, this article changes the initial assumptions of investors accordingly and sets them as: $P_{1}=P_{2}=1.5, \gamma=1, \alpha_{1}=\alpha_{2}=0.7$, and other assumptions remain unchanged. The simulation result is shown in Figure 3.

It can be seen from Figure 3 that when $\gamma\left(P_{2}-P_{0}\right)^{\alpha_{2}}-(1-\gamma) \lambda\left(P_{0}-P_{3}\right)^{\beta}>0$ and $\left(P_{1}-P_{0}\right)^{\alpha_{1}}>0$, the investors' strategic choices will gradually become "speculation". Since the local government has not yet issued the latest regulation policies, the local government's strategic choice is consistent with the choice at the previous stage, that is, "no regulation". The above results show that when policy dividends appear and policy regulation is lagging, the investors' perceived value of the housing is only affected by market optimism. At this time, optimism generates positive incentives for housing speculation, leading to a large number of housing purchases in the housing market, and promoting a rapid rise in housing prices. Therefore, the equilibrium result of the game at this stage is (no regulation, speculation). At this stage, as favorable policies have just been released, the number of investors in the housing market is still relatively small. From the perspective of economic costs, the local government is more inclined to not regulate. At this time, the local government can actively guide public opinion and media propaganda to prevent the spread of housing speculation.

\subsection{Numerical Simulation Analysis in the Bubble Formation Stage}

The period from 14 April to 21 April represents the formation and expansion stage of the housing bubble. With the continuous enlargement of market optimism, the rapid increase of investors in the housing market in Hainan province has further strengthened investors' psychological expectations of rising housing prices. On the basis of the previous stage, the assumptions are set as: $P_{1}=P_{2}=2.5, \alpha_{1}=\alpha_{2}=0.9$, and other assumptions remain unchanged. The simulation result is shown in Figure 4.

It can be seen from Figure 4 that as the investors' psychological expectations of rising housing prices are further strengthened, compared with the previous stage, investors will make "speculative" strategic choices faster. However, due to the short time of bubble generation, the local governments do not have enough time to respond, so its strategic choice is still "no regulation". The above results indicate that the continuous spread of favorable effects of the policies in Hainan province has attracted a large number of housing investors from all over the country in a short time. In the absence of effective intervention by the local government, the housing prices in Hainan province have continued to rise. Therefore, the equilibrium result of the game at this stage is (no regulation, speculation). At this stage, the number of housing investors has increased significantly. The higher-level government can increase the penalties expressed by $F_{1}$ for local governments' inaction to make $F_{1}>C+F_{2}+W_{2}-W_{1}$, to promote local governments to actively maintain the order of the housing market, which helps reduce the investors' perceived value of the housing. 


\subsection{Numerical Simulation Analysis in the Bubble Expansion Stage}

Over time, local governments have gradually realized the negative impact of out-ofcontrol housing prices, as well as the severe penalties and social losses they will bear if they do not regulate them. Accordingly, this article changes the relevant parameters of the local government accordingly, assuming $F_{1}=2, F_{2}=1, W_{1}=2, W_{2}=1, W_{3}=1.5$, $R=1.5, C=1$. Affected by policy regulation, market pessimism began to rise. Meanwhile, the increase in speculative risks has reduced investors' psychological expectations of rising housing prices and increased investors' psychological expectations of falling housing prices. Accordingly, this article adjusts the relevant parameters of investors, assuming $P_{2}=2$, $P_{3}=0.8, \lambda=1.5, \gamma=0.7, \alpha_{2}=0.6, \beta=0.6$, and other assumptions remain unchanged. The simulation result is shown in Figure 5.

It can be seen from Figure 5 that when $-C-F_{2}-W_{2}>-F_{1}-W_{1}$ and $R-C+W_{3}>0$, the local governments will gradually tend to choose "regulation." When $\gamma\left(P_{2}-P_{0}\right)^{\alpha_{2}}-$ $(1-\gamma) \lambda\left(P_{0}-P_{3}\right)^{\beta}>0$ and $\left(P_{1}-P_{0}\right)^{\alpha_{1}}>0$, the investors still tend to choose "speculation". The above results indicate that the rapid rise in housing prices has forced local governments to intervene in the housing market. At this time, the housing market is affected by both optimism and pessimism, and the rising trend of housing prices has slowed down compared with the previous stage. However, due to the relatively weak regulation by the local government in the early stage, the investors' perceived value of the housing is still positive, which makes housing speculations continue. Therefore, the equilibrium result of the game at this stage is (regulation, speculation). At this stage, the local government's regulation is not enough to restrain investors' speculation. Accordingly, on the one hand, the local government can reduce the psychological expectations of investors for rising housing prices by increasing the regulation of housing prices. On the other hand, the local government can intensify its crackdown on housing speculation and increase the speculative risk of investors to reduce the occurrence of speculation.

\subsection{Numerical Simulation Analysis in the Bubble Burst Stage}

On 22 April 2018, Hainan province issued a notice on further stabilizing the housing market, announcing the implementation of the global purchase restriction based on the original regulation policies from now on. Soon, the rising trend of housing prices in Hainan province was curbed. On the one hand, the local government strengthened its regulation, and its regulation cost also increased. On the other hand, stricter regulation policies have further expanded market pessimism and correspondingly increased the risk of housing speculation. Those have led to relatively lower psychological expectations of investors for rising housing prices and higher psychological expectations for falling housing prices. Accordingly, this article assumes $C=1.5, P_{2}=1.5, P_{3}=0.6, \lambda=1.7, \gamma=0.3, \alpha_{2}=0.3$, $\beta=0.7$, and other assumptions remain unchanged. The simulation result is shown in Figure 6 .

It can be seen from Figure 6 that when $-C-F_{2}-W_{2}>-F_{1}-W_{1}$ and $R-C+W_{3}>0$, the local governments will gradually tend to choose "regulation." Since $\gamma\left(P_{2}-P_{0}\right)^{\alpha_{2}}-$ $(1-\gamma) \lambda\left(P_{0}-P_{3}\right)^{\beta}<0$, with the extension of time, the investors will tend to choose "no speculation". The above results show that when the local government continues to strengthen the regulation, the market sentiment will gradually reverse, and the rise of pessimism will lead to the decline in the investors' perceived value of the housing. When investors' perceived value of the housing is negative, housing speculation will gradually disappear. Therefore, the equilibrium result of the game at this stage is (regulation, no speculation). At this stage, when speculation in the housing market is effectively curbed, local governments should pay attention to the dynamic changes in market sentiment, comprehensively evaluate the regulatory effect, and timely adjust regulation policies. To ensure the stability of the housing market, we should not only avoid the rapid rise of housing prices caused by the recurrence of housing speculation, but also avoid the rapid fall of housing prices caused by excessive housing regulation. 


\section{Conclusions and Policy Implications}

\subsection{Conclusions}

The housing bubble is caused by the combination of policy environment and participant behavior. Due to the interaction between speculation, regulation, and market sentiment elements, the development and evolution of the housing bubble is faced with uncertainty. Different from traditional econometric analysis, this article adopts the evolutionary game analysis method to establish a multi-stage evolutionary game analysis framework for the housing bubble. First of all, by analyzing the emotional perceived value of related subjects under optimism, pessimism, and uncertainty, this article explores the mechanism of emotional perceived value on the housing bubble under the condition of inconsistent policy objectives. Secondly, it introduces emotional perceived value into the evolutionary game analysis framework of housing bubbles, and analyzes the strategic combination and game equilibrium between investors and local governments under different emotions. Finally, taking Hainan province as an example, it conducts MATLAB numerical simulation on the uncertain evolution of the housing bubble and proposes a staged strategy combination to deal with the housing bubble. The conclusions are as follows:

First, the emotional perceived value is affected by the policy environment. Market sentiment is affected by both favorable policies and regulation policies. Favorable policies stimulate investors' optimism, and then enhance investors' psychological expectations for rising housing prices. The regulation policies stimulate investors' pessimism, generate speculative risks, and then enhance investors' psychological expectations for falling housing price. The changes in the strength of the two policies have caused market sentiment to fluctuate between optimism and pessimism, which further affects investors' perceived value of the housing.

Second, the changes in the strength of policy effects makes the emotional perceived value change, which has different incentive effects on investors' speculation and local governments' regulation. Optimism generates positive incentives for housing speculation and promotes the housing bubble. Pessimism produces negative incentives for housing speculation and has an inhibitory effect on the housing bubble. When both favorable policies and regulation policies are implemented at the same time, market sentiment will face uncertainty. The effects of the two policies will influence each other, thereby regulating the expansion and contraction of the housing bubble.

Third, there are differences in emotional perceived value in different stages, which improves the uncertainty of the game equilibrium result between investors and local governments. According to evolutionary game analysis, there are five possible equilibrium results: in the bubble-free stage, the equilibrium result is (no regulation, speculation/no speculation). In the bubble germination stage, the equilibrium result is (no regulation, speculation). In the bubble formation stage, the equilibrium result is (no regulation, speculation). In the bubble expansion stage, the equilibrium result is (regulation, speculation). In the bubble burst stage, the equilibrium result is (regulation, no speculation).

\subsection{Policy Implications}

Based on the above conclusions and MATLAB numerical simulation results, this article puts forward the following countermeasures and suggestions to prevent and control the housing bubble:

(1) In the bubble-free stage, the behavior of housing investors is less affected by market sentiment and is more affected by market factors. the local government can strengthen the monitoring of house price fluctuations and market transaction volume before the release of favorable policies, so as to make adequate preparations for the possible housing speculation after the release of favorable policies; (2) in the bubble germination stage, the investors' perceived value of the housing is only affected by market optimism. The number of investors at this stage is relatively small, and the local government is more inclined to not regulate. The local government can actively guide public opinion and media propaganda to prevent the spread of housing speculation; (3) in the bubble formation stage, with a large 
number of investors entering the housing market in Hainan province within a short time, housing prices have been rising. The higher-level government can increase the penalties for the local governments' inaction to promote local governments to actively maintain the order of the housing market, which helps reduce the investors' perceived value of the housing; (4) in the bubble expansion stage, the local government's regulation and intervention on the housing market makes it affected by both optimism and pessimism. However, the local government's regulation is not enough to restrain investors' speculation. Accordingly, on the one hand, the local government can reduce the psychological expectations of investors for rising housing prices by increasing the regulation of housing prices. On the other hand, the local government can intensify its crackdown on housing speculation and increase the speculative risk of investors to reduce the occurrence of speculation; and (5) in the bubble burst stage, the local government has effectively curbed the housing speculation by strengthening the regulation. The local government should pay attention to the dynamic changes in market sentiment, comprehensively evaluate the regulatory effect, and timely adjust regulation policies. To ensure the stability of the housing market, we should not only avoid the rapid rise of housing prices caused by the recurrence of housing speculation, but also avoid the rapid fall of housing prices caused by excessive housing regulation.

Author Contributions: Conceptualization, Y.T. and K.H.; methodology, Y.T. and K.H.; validation, Y.Z. (Yucheng Zou) and Y.Z. (Yanwei Zhang); writing-review \& editing, Y.Z. (Yucheng Zou) and Y.Z. (Yanwei Zhang). All authors have read and agreed to the published version of the manuscript.

Funding: This research was funded by the National Natural Science Foundation of China (No. 71671187).

Data Availability Statement: Not applicable.

Acknowledgments: The authors wish to thank the anonymous reviewers and the Editors, whose insightful comments and helpful suggestions significantly contributed to improving this paper.

Conflicts of Interest: The authors declare no conflict of interest.

\section{References}

1. Zhou, J.C. Real estate: Property evolution, investment activities and market evolution. Financ. Trade Econ. 2007, 8, 115-120.

2. Kivedal, B.K. Testing for rational bubbles in the US housing market. J. Macroecon. 2013, 38, 369-381. [CrossRef]

3. Jiang, C.H. A case study of the speculation bubble on China's real estate market. Manag. World 2005, 12, 71-84.

4. Sun, J.G.; Zhao, X. Research on Beijing's real estate price bubble: Analysis based on the speculative bubble test model. Price Theory Pract. 2010, 12, 46-47.

5. Yi, X.R. The transformation of the "real estate" economy and the establishment of a long-term real estate mechanism. Explor. Free Views 2017, 8, 108-114.

6. Rajan, R.G. Fault lines: How hidden fractures still threaten the world economy. Econ. Books 2010, 23, 151-155.

7. Wei, R.H.; Jin, L.; Fang, D. Study on the Spatial Infection of Real Estate Market Bubble Based on GIS in China: Case Study of 35 Metropolises in 2006 and 2014. Resour. Environ. Yangtze Basin 2018, 27, 1967-1976.

8. Yu, X. Research on Real Estate Price Bubble and Turning Point-Comparative Analysis Based on Tokyo, Japan and Shanghai, China. Manag. Rev. 2019, 31, 58-69.

9. Zheng, H.T.; He, J.Z.; Lin, L.; Zhang, W.R.; Ren, R.E. Super exponential inflation model for bubble identification in housing market: Taking the housing prices in various districts and counties of Beijing and Shanghai as an example. Syst. Eng. Theory Pract. 2018, 38, 585-593.

10. Ahmed, R.; Jawaid, S.T.; Khalil, S. Bubble Detection in Housing Market: Evidence from a Developing Country. Sage Open 2021, 11,1-11. [CrossRef]

11. Long, D.; Bradford, J.; Shleifer, A.; Summers, L.H.; Waldmann, R.J. Noise trader risk in financial markets. J. Political Econ. 1990, 98, 703-738. [CrossRef]

12. Bangura, M.; Lee, C.L. House price diffusion of housing submarkets in Greater Sydney. Hous. Stud. 2020, 35, 1110-1141. [CrossRef]

13. Clapp, J.M.; Salavei, K. Hedonic pricing with redevelopment options: A new approach to estimating depreciation effects. J. Urban Econ. 2010, 67, 362-377. [CrossRef]

14. Hirshleifer, J. Reply to comments on "speculation and equilibrium: Information, risks, and markets". Q. J. Econ. 1975, 89, 519-542. [CrossRef]

15. Feiger, G. What is speculation? Q. J. Econ. 1976, 90, 667-687. [CrossRef] 
16. Kindleberger, C.P.; Aliber, R.Z. Manias Panics and Crashes: A History of Financial Crises; John Wiley \& Sons: New York, NY, USA, 2000.

17. Xu, D.Q. House Prices and Bubble Economy; Machinery Industry Press: Beijing, China, 2006.

18. Wang, S.X. Economic effect analysis of two demands of customers in real estate market. J. Yunnan Univ. Financ. Econ. 2007, 1, 112-115.

19. Bangura, M.; Lee, C.L. Housing price bubbles in Greater Sydney: Evidence from a submarket analysis. Hous. Stud. 2020, 1-36. [CrossRef]

20. Pawson, H.; Martin, C. Rental property investment in disadvantaged areas: The means and motivations of Western Sydney's new landlords. Hous. Stud. 2020, 4, 1-23. [CrossRef]

21. Long, J.Y. Discussion on the factors influencing the fluctuation of house price in China and the countermeasures-Also on the positive and negative effects of self occupied house purchase and real estate speculation. Price Theory Pract. 2010, 7, 32-33.

22. Blanchard, O.; Mark, W. Bubbles, Rational Expectations and Financial Markets. Crisis in the Economic and Financial Structure; NBER Working Papers; NBER: Cambridge, MA, USA, 1982.

23. Dou, E.X.; Li, H.T.; Li, X.Y. Analysis of the factors causing the price bubble in China's real estate market. J. Grad. Sch. Chin. Acad. Soc. Sci. 2007, 1, 40-45.

24. Kuang, W.D. Expectation, speculation and urban house price volatility in China. Econ. Res. 2010, 45, 67-78.

25. Brunnermeier, D.M. Bubbles and crashes. Econometrica 2003, 71, 173-204.

26. Li, X. Research on the formation mechanism of bubble economy. Econ. Manag. Res. 2007, 7, 33-37.

27. Wang, Y.Q.; Bao, T. Heterogeneous traders, real estate bubbles and real estate policies. World Econ. 2011, 11, 86-104.

28. Case, K.; Shiller, R. Is there a bubble in the housing market? Brook. Pap. Econ. Act. 2003, 2, 299-342. [CrossRef]

29. Zhou, J.K.; Cao, Z.L. Foaming and non-foaming in Chinese real estate market-An empirical analysis based on speculative theory. J. Shan Xi Financ. Econ. Univ. 2004, 26, 53-57.

30. Yu, H.Y. Are economic fundamentals or real estate policies affecting China's housing prices? Financ. Trade Econ. 2010, 3, 116-122.

31. Huang, X.; Dong, X.; Ping, X.Q. Policy evaluation of local government real estate market regulation based on restriction of purchase, loan and sale. Reform 2018, 291, 109-120.

32. Liu, J.T.; Zhang, B.; Huang, Z.G. Purchase restriction policy and the dynamic changes of housing price. Econ. Dev. 2012, 3, 47-54.

33. Han, Y.H.; Zhang, Z.M.; Zou, J.H. The analysis on the influence mechanism and policy perspective of the housing restriction policy on China's urban housing prices-Based on single Center-dual cycle city model. Econ. Theory Econ. Manag. 2016, 7, 16-28.

34. Li, Y.X.; Tian, L.; Yang, M. Does the home purchase restriction policy lower the growth rate of house prices? Syst. Eng. Theory Pract. 2019, 39, 906-921.

35. Chen, J.; Gao, J. Real estate price index fluctuation and its empirical test. Stat. Decis. 2016, 10, 11-15.

36. Wang, M.; Huang, Y. The impact of purchase restrictions and real estate tax on housing prices: An analysis based on long-term dynamic equilibrium. World Econ. 2013, 1, 141-159.

37. Zhang, Y. An empirical study on the influence of currency liquidity policy on real estate price volatility. Stat. Decis. 2015, 12, 121-123.

38. An, H.; Wang, R.D. An empirical analysis of influencing factors in real estate prices of China and the current real estate regulating policy. Sci. Financ. Econ. 2013, 3, 115-124.

39. Yi, B. Housing-demand suppression or land-supply adjustment: A comparison of real estate control policy. J. Financ. Econ. 2015, $41,66-75$.

40. Wang, X.Z.; Yang, Y.W. Differentiated expectations, policy regulation and housing price fluctuations: An empirical study of 35 large and medium-sized cities in China. Financ. Res. 2015, 41, 51-61.

41. Sheng, S.C.; Long, Y. An effective way to control housing prices is to pay equal attention to supply and demand. China Financ. 2016, 21, 16-18.

42. Elster, J. Social Norms and Economic Theory. J. Econ. Perspect. 1989, 3, 99-117. [CrossRef]

43. Virlics, A. Investment decision making and risk. Procedia Econ. Financ. 2013, 6, 169-177. [CrossRef]

44. Song, S.L.; Wang, Y.C. How does investor sentiment affect stock pricing? An empirical research based on IPO firms. J. Manag. Sci. China 2016, 19, 41-55.

45. Burnside, C.; Eichenbaum, M.; Rebelo, S. Understanding booms and busts in housing markets. J. Political Econ. 2016, 124, 1088-1147. [CrossRef]

46. Hu, C.S.; Peng, Z.; Chi, Y.C. Feedback trading, trading inducement and asset price behavior. Econ. Res. 2017, 52, 189-202.

47. Luo, B.Y.; Yang, C.H. Environmental uncertainty, investor sentiment and corporate investment efficiency. Financ. Account. Mon. 2020, 24, 33-41.

48. Shiller, R.J. Understanding Recent Trends in House Prices and Home Ownership; Working Paper; National Bureau of Economic Research: Cambridge, MA, USA, 2007; Volume 13553.

49. Xiong, W. Bubbles, Crises, and Heterogeneous Beliefs; Working Paper; National Bureau of Economic Research: Cambridge, MA, USA, 2013; Volume 18905.

50. Lee, C.L.; Reed, R. Volatility decomposition of Australian housing prices. J. Hous. Res. 2014, 23, 21-43. [CrossRef]

51. Hirshleifer, D.; Teoh, S.H. Limited attention, information disclosure, and financial reporting. J. Account. Econ. 2003, 36, 337-386. [CrossRef] 
52. Kaplanski, G.; Levy, H. Sentiment and stock prices: The case of aviation disasters. J. Financ. Econ. 2010, 95, 174-201. [CrossRef]

53. Shiller, R. Irrational Exuberance; Princeton University Press: Princeton, NJ, USA, 2015.

54. Huang, Y.F.; Hong, W.B.; Yu, H.Y. How does the market sentiment affect urban housing price. Econ. Theory Bus. Manag. 2019, 7, 75-88.

55. Liu, L.; Chen, N. Market investor sentiment and China's house price fluctuation: Empirical research based on the model of Markov mechanism switching VAR. Math. Pract. Theory 2017, 22, 58-67.

56. Leng, Y.P.; Huang, S.G. Research on the impact of investor sentiment on housing prices-An empirical analysis based on VAR model. Product. Res. 2020, 6, 31-34.

57. Fang, Y.Q.; Tai, Y.H.; Bai, J.M. Consumer sentiment, economic policy uncertainty and real estate price fluctuation. Econ. Res. Guide 2020, 450, 7-10.

58. Yao, Y.; Jiang, Y.F.; Zhai, J. Investor sentiment and optimizing risk multiplier of CPPI. Manag. Rev. 2018, $30,43-57$.

59. Guo, D.Y.Z. Investor sentiment and volatility asymmetry. Financ. Econ. 2017, 11, 43-52.

60. Chen, Q.A.; Lei, X.Y. Monetary policy, investor sentiment and volatility of Chinese stock market: Theory and evidence. Chin. J. Manag. Sci. 2017, 25, 1-11.

61. Yin, H.Y.; Lu, L. Liquidity cost, market sentiment and asset allocation behavior: An analysis model under uncertainty. J. Cent. Univ. Financ. Econ. 2017, 5, 48-57.

62. Hui, E.; Dong, Z.; Jia, S.H.; Lam, C. How does sentiment affect returns of urban housing? Habitat Int. 2017, 64, 71-84. [CrossRef]

63. Ghosh, S. Housing price volatility: Uncertainty, an asymmetric econometric analysis-Some European country experiences. Int. J. Hous. Mark. Anal. 2021. ahead-of-print. [CrossRef]

64. Kim, K.H.; Renaud, B. The global house price boom and its unwinding: An analysis and a commentary. Hous. Stud. 2009, 24, 7-24. [CrossRef]

65. Loutskina, E.; Strahan, P.E. Financial integration, housing, and economic volatility. J. Financ. Econ. 2015, 115, 25-41. [CrossRef]

66. Hatemi-j, A. Asymmetric causality tests with an application. Empir. Econ. 2012, 43, 447-456. [CrossRef]

67. Baker, S.R.; Bloom, N.; Davis, S.J. Measuring economic policy uncertainty. Q. J. Econ. 2016, 123, 1593-1636. [CrossRef]

68. Hardouvelis, G.A.; Karalas, G.; Karanastasis, D.; Samartzis, P. Economic policy uncertainty, political uncertainty and the Greek economic crisis. Political Uncertainty and the Greek Economic Crisis. SSRN 2018. [CrossRef]

69. Posedel, P.; Vizek, M. The Nonlinear House Price Adjustment Process in Developed and Transition Countries. Financ. Uver Czech J. Econ. Financ. 2011, 61, 584-600.

70. Begiazi, K.; Katsiampa, P. Modelling UK house prices with structural breaks and conditional variance analysis. J. Real Estate Financ. Econ. 2019, 58, 290-309. [CrossRef]

71. Zhou, J.K. Belief, Feedback Effect and Game Equilibrium: A Game Theory Explanation of the Speculative Bubble of Real Estate. World Econ. 2005, 5, 21-27.

72. Ouyang, H. An analysis of game theory on the functions of real estate "Market Forces". J. Contemp. Financ. Econ. 2009, 8, 87-91.

73. Bao, T.; Hommes, C. When speculators meet suppliers: Positive versus negative feedback in experimental housing markets. $J$. Econ. Dyn. Control 2019, 107, 103730. [CrossRef]

74. Bolt, W.; Demertzis, M.; Diks, C.; Hommes, C.; Leij, M. Identifying booms and busts in house prices under heterogeneous expectations. Soc. Sci. Electron. Publ. 2019, 103, 234-259. [CrossRef]

75. Ellen, S.T.; Hommes, C.H.; Zwinkels, R. Comparing behavioural heterogeneity across asset classes. J. Econ. Behav. Organ. 2020, 185, 747-769. [CrossRef]

76. Martin, C.; Schmitt, N.; Westerhoff, F. Heterogeneous expectations, housing bubbles and tax policy. J. Econ. Behav. Organ. 2021, 183, 555-573. [CrossRef]

77. Song, C.Y.; Zhang, Q. The formation mechanism of the real estate bubble-An analysis based on the perspective of behavioral economics. Urban Probl. 2009, 1, 51-56.

78. Xiu, L.N.; Liu, X.N.; Huang, L.X. An empirical analysis of the real estate bubble-A case study in Tianjin. Urban Dev. Stud. 2009, 16, 71-75.

79. Hu, W.X.; Liu, G.; Zhang, W.G.; Fu, Q. Study on evolution of irrational asset price bubbles generation and expansion based on factors embedded. Chin. J. Manag. Sci. 2016, 24, 31-37.

80. Du, P.; Ma, B. Influencing factors of Chinese urban residents' housing policy preferences. Econ. Manag. Res. 2018, $39,88-99$.

81. Friedman, D. On economic applications of evolutionary game theory. J. Evol. Econ. 1998, 8, 15-43. [CrossRef]

82. Wang, Z.Y.; Nie, H.F.; Zhao, H.L. Multi-stage emergency decision-making method considering the decision-maker's emotional update mechanism. Control Decis. 2020, 35, 436-444. 